\title{
Pengaruh Karakter Kerja Keras terhadap Hasil Belajar Fisika di SMA Negeri 1 Kota Jambi
}

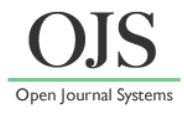

\author{
Endah Febri Setiya Rini*, Riska Fitriani, Maria Marisa Matondang, Fauziah Yolviansyah, \\ Novita Dwi Putri, Falentina Loveria Agatha, Nola Lolita \\ Prodi Pendidikan Fisika, Universitas Jambi \\ *Email: endahfebri9@gmail.com
}

DOI: https://doi.org/10.33369/pendipa.5.2.256-261

\begin{abstract}
This research used quantitative research, using instruments in the form of hard work questionnaires and multiple-choice questions of physics material. Meanwhile, the purpose of this study is to influence the character of hard work on student achievement. The subjects of this study were students of class XII MIPA at SMA Negeri 1 Jambi City in the 2020/2021 academic year. This study uses a survey method. The data analysis technique in this study used the SPSS program by testing normality, correlation, and simple linear regression. It can be seen that the significance results in the hard work trial of physics learning outcomes obtained 0.000. From these results it can be seen that $0.000<0.05$, which means that the two variables are correlated. Then, in terms of the Pearson correlation, the result is 0.927, which means that the degree of relationship or the value of the Pearson correlation is in the very strong category. That is, the level of student hard work in physics is very related and influences student learning outcomes. Then, a simple linear regression test was also performed with the results of the regression equation analysis $Y=-3.33+$ $0.943 X$. tcalc $=15.235$ and $p$-value $=0.000 / 2=0.000<0.05$. The results showed that there was an influence between the character of hard work on student learning outcomes, especially in the cognitive aspects.
\end{abstract}

Keywords: Character; Hardwork; Achievment; Education; Physics.

\begin{abstract}
ABSTRAK
Jenis penelitian yang digunakan adalah penelitian kuantitatif dengan menggunakan instrumen berupa angket kerja keras dan soal pilihan ganda materi fisika. Adapun, tujuan dari penelitian ini yaitu untuk mengetahui pengaruh karakter kerja keras terhadap hasil belajar siswa. Subjek penelitian ini adalah siswa kelas XII MIPA di SMA Negeri 1 Kota Jambi tahun ajaran 2020/2021. Penelitian ini menggunakan metode survey. Teknik analisis data pada penelitian ini menggunakan program SPSS dengan melakukan pengujian normalitas, korelasi, dan juga regresi linear sederhana. Dapat di lihat hasil signifikansi pada uji korelasi karakter kerja keras terhadap hasil belajar fisika didapatkan 0,000. Dari hasil tersebut dapat di lihat bahwa $0,000<0,05$ yang artinya kedua variabel berkorelasi. Kemudian, ditinjau pada pearson correlation didapatkan hasil 0,927 yang berarti derajat hubungan atau nilai pearson correlation masuk pada kategori korelasi sangat kuat. Artinya, tingkat kerja keras siswa dalam mata pelajaran fisika sangat berhubungan dan berpengaruh pada hasil belajar siswa. Kemudian, dilakukan pula uji regresi linear sederhana dengan hasil analisis diperoleh persamaan regresi $\mathrm{Y}=-3,33+0,943 \mathrm{X} . \mathrm{t}_{\text {hit }}=15,235$ dan $\mathrm{p}$-value $=0,000 / 2=0,000<$ 0,05 . Hasil penelitian menunjukkan adanya pengaruh antara karakter kerja keras terhadap hasil belajar siswa, khususnya pada aspek kognitif.
\end{abstract}

Kata kunci: Karakter; Kerja Keras; Prestasi; Pendidikan; Fisika. 


\section{PENDAHULUAN}

Pendidikan merupakan suatu kebutuhan yang amat penting di Era ini. Kompetisi di era globalisasi sangatlah ketat sehingga dibutuhkan kelebihan dalam diri seseorang (Idris, 2020). Pendidikan menjadi ladang kebutuhan sekaligus tuntutan yang tidak bisa terabaikan (Sari, 2020). Karena pada dasarnya, generasi muda bukan hanya sebagai pengguna namun sangat diperlukan sebagai pencipta, hal itulah yang mendasari bahwa pendidikan memegang peran yang begitu penting (Martawijaya, 2019). Oleh sebab itu, pendidikan termasuk kebutuhan primer yang wajib dipenuhi oleh tiap individu (Mangamar, 2019). Menurut Kurniawan (2018), Pendidikan merupakan suatu proses dalam rangka peningkatan kualitas kehidupan dan keterampilan. Pendidikan juga termasuk salah satu program pemerintah untuk meningkatkan potensi individu ataupun masyarakat guna mempersiapkan sumber daya manusia untuk masa sekarang dan masa depan (Mafudiansyah, 2020).

Kegiatan pembelajaran dalam suatu pendidikan, khususnya pada pendidikan formal yang bertempat di sekolah adalah interaksi aktif antar pendidik dan peserta didik (Marzuki, 2020). Salah satu indikator keberhasilan suatu sistem pendidikan yaitu dengan melihat prestasi / hasil belajar peserta didik (Putri, 2018; Rini dkk, 2020). Kegiatan pembelajaran menghasilkan peserta didik dengan prestasi belajar dari tingkatan yang kurang baik dan juga prestasi belajar yang baik (Sarlin, 2018). Dimaksudkan hasil belajar apabila terjadi perubahan tingkah laku dalam diri siswa yang dapat diamati dan dapat terukur dalam bentuk perubahan keterampilan, pengetahuan, dan sikap (Pangestu, 2015).

Fisika adalah salah satu unsur yang utama untuk pembangunan dan mewujudkan IPTEK (Ariani, 2017). Pada dasarnya, kemampuan fisika adalah kemampuan yang sudah dimiliki dalam mata pelajaran fisika, khususnya kemampuan untuk menyelesaikan dan memecahkan soal fisika (Wijaya, 2019). Kemudian, pembelajaran fisika sendiri mencakup dua kategori seperti proses dan hasil, peserta didik tidak hanya mengingat apa yang telah dipelajari melainkan juga perlu memahami konsep secara benar (Thahir, 2019). Namun, tantangan pada saat ini yaitu, banyak siswa SMA mengaggap bahwa mata pelajaran fisika merupakan mata pelajaran yang membosankan dan kurang menarik untuk dipelajari (Al Munawwarah, 2018). Dalam meningkatkan hasil belajar fisika, maka dibutuhkan suatu cara untuk membuat siswa termotivasi dalam belajar agar hasil belajar peserta didik maksimal (Layuk, 2020). Apabila siswa sudah memiliki kesenangan belajar fisika, maka ia akan tertarik untuk meluangkan waktu dalam pembelajaran Fisika (Putra, 2019).

Namun, sejalan dengan perkembangan zaman dan berkembangnya teknologi mengakibatkan adanya pergeseran perilaku menyimpang (Silahuddin, 2017). Sehingga, kompetensi sikap berdasarkan kurikulum 2013 terbagi menjadi dua yakni sikap spiritual dan sikap sosial yang mengarah pada pembentukan karakter (Arham, 2020). Oleh sebab itu, pendidikan karakter sangatlah dibutuhkan pada era ini. Khususnya, karakter kerja keras (Lasmita, 2019). Karakter kerja keras bisa melatih siswa untuk selalu berusaha, bersungguh-sungguh, tidak menyerah, dan tak kenal lelah (Sari, 2019). Dan di harapkan peserta didik juga menerapkan karakter kerja keras di dalam pembelajaran fisika agar mendapat hasil belajar yang maksimal. Sebab, telah diyakini bahwa apabila siswa memiliki karakter kerja keras yang tinggi dalam pembelajaran fisika akan mempengaruhi hasil belajar siswa tersebut (Fitriani dkk., 2020).

Tujuan penelitian ini, yakni untuk mengetahui pengaruh kerja keras dalam mata pelajaran fisika terhadap hasil belajar peserta didik. Pertanyaan yang di tujukan yaitu:

1. Bagaimana hubungan kerja keras dalam mata pelajaran fisika terhadap hasil belajar peserta didik, serta

2. Apakah terdapat pengaruh kerja keras terhadap hasil belajar peserta didik dalam mata pelajaran fisika.

Dengan mengetahui hubungan dan pengaruh karakter kerja keras terhadap hasil belajar peserta didik. Dapat memberikan pengalaman bagi guru untuk mengetahui kerja keras siswa yang dapat memudahkan guru untuk mengatur strategi, metode dan model ataupun media yang cocok untuk diberikan pada saat proses pembelajaran fisika. 


\section{METODE PENELITIAN}

Jenis penelitian ini yaitu penelitian kuantitatif. Penelitian kuantitatif bertujuan untuk memberikan secara jelas mengenai gambaran masalah yang teliti serta dapat menjelaskan data secara jelas dan sistematis (Pratomo dan Setyowati, 2016). Penelitian kuantitatif merupakan penelitian yang berguna untuk meneliti sampel dari suatu populasi yang pada umumnya diambil dari sampel acak melalui instrumen yang kemudian didapatkan data dan diolah serta dianalisis secara kuantitatif ataupun statistik (Ramadhan, 2019). Penelitian ini menggunakan metode survey. Metode survey adalah metode yang sering digunakan oleh masyarakat ilmiah dalam penelitiannya (Adiyanta, 2019). Subjek penelitian ini adalah siswa kelas XII MIPA 1 dan XII MIPA 2 di SMA Negeri 1 Kota Jambi tahun ajaran 2020/2021. Teknik pengumpulan data dilakukan dengan dua cara yakni pemberikan tes hasil belajar fisika pada materi fluida dinamis, berupa soal pilihan ganda yang di adopsi dari angket skripsi Quanti (2017). Pengumpulan pemberian kuesioner soal fisika tersebut bertujuan untuk mengetahui konsep yang dipahami peserta didik, dan selanjutnya adalah pemberian angket kerja keras melalui skala likert dimana terdapat pernyataan positif dan juga negatif dan di nilai dengan lima indikator; sangat tidak setuju, tidak setuju, netral, setuju, dan sangat setuju (Sappaile, 2007). Analisis data pada penelitian ini menggunakan program SPSS berupa Uji normalitas, Uji korelasi dan juga Uji regresi linear sederhana.

\section{HASIL DAN PEMBAHASAN}

Penelitian ini diambil data dari kelas XII MIPA di SMA Negeri 1 Kota Jambi, khusus nya XII MIPA 1 dan XII MIPA 2 pada tahun ajaran 2020/2021. Angket yang digunakan terdapat dua jenis yaitu angket kerja keras siswa dalam mata pelajaran fisika dan angket hasil belajar siswa. tujuan penelitian ini, yakni untuk mengetahui mengetahui pengaruh kerja keras dalam mata pelajaran fisika terhadap hasil belajar fisika peserta didik. Untuk melihat hubungan ataupun pengaruh kerja keras siswa terhadap hasil belajar maka harus di Uji Normalitas terlebih dahulu, uji normalitas merupakan uji yang digunakan agar kita dapat mengetahui apakah variabel memiliki data yang berdistribusi normal atau tidak yang nantinya menjadi syarat untuk dapat melakukan uji korelasi dan juga uji regresi linear sederhana (Harahap, 2017) dan setelah melakukan pengujian maka di dapatkan hasil seperti pada tabel 1 .

Tabel 1. Hasil Uji Normalitas

\begin{tabular}{lll}
\hline & Sig. & $\begin{array}{l}\text { Berdistribusi } \\
\text { Normal }\end{array}$ \\
\hline $\begin{array}{l}\text { Kerja Keras Fisika } \\
\text { XII MIPA 1 }\end{array}$ & 0,048 & Normal \\
$\begin{array}{l}\text { Kerja Keras Fisika } \\
\text { XII MIPA 2 }\end{array}$ & 0,112 & Normal \\
$\begin{array}{l}\text { Hasil Belajar Fisika } \\
\text { XII MIPA 1 }\end{array}$ & 0,122 & Normal \\
$\begin{array}{l}\text { Hasil Belajar XII } \\
\text { MIPA 2 }\end{array}$ & 0,200 & Normal \\
\hline
\end{tabular}

Dari hasil Tabel 2 diatas menyajikan hasil uji normalitas, dengan nilai Asymp. Sig. (2-tailed) untuk kerja keras dalam pelajaran fisika kelas XII MIPA 1 adalah 0,048, dan hasil kerja keras dalam pelajaran fisika kelas XII MIPA 2 adalah 0,112. Sedangkan, nilai Asymp. Sig. (2-tailed) untuk hasil belajar fisika kelas XII MIPA 1, yaitu 0,122 dan untuk hasil belajar fisika kelas XII MIPA 2, yaitu 0,200. Menurut (As'ari, 2018), syarat pedoman untuk mengambil keputusan normailtas dengan uji normalitas Kolmogorov-Smirnov dalam SPSS, yaitu;

1. Nilai Signifikansi ataupun nilai probabilitas $<0,05$ maka data tersebut tidak normal.

2. Nilai Signifikansi ataupun probabilitasnya $>0,05$ maka data tersebut dapat dikatakan normal.

Sehingga dengan demikian, dapat disimpulkan bahwa data karakter kerja keras dan data hasil belajar tersebut berdistribusi normal, karena hasil uji yang telah dilakukan menunjukkan bahwa data memiliki nilai signifikansi lebih besar dari 0,05.

Setelah dilakukan uji normalitas terhadap data kuantitatif karakter kerja keras dan hasil belajar fisika, hal yang selanjutnya dilakukan adalah melakukan uji korelasi untuk mengetahui 
hubungan antara karakter kerja keras terhadap hasil belajar siswa. Hasil Pengujian korelasi disajikan dalam Tabel 2.

Tabel 2. Hasil Uji Korelasi Pearson

\begin{tabular}{llll}
\hline & Sig. & $\begin{array}{l}\text { Kerja } \\
\text { Keras }\end{array}$ & $\begin{array}{l}\text { Hasil } \\
\text { Belajar }\end{array}$ \\
\hline Kerja & Pearson & 1 & 0,927 \\
Keras & Correlation & & 0,000 \\
& Sig. (2-tailed) & & \\
Hasil & Pearson & 0,927 & 1 \\
Belajar & Correlation & 0,000 & \\
& Sig. (2-tailed) & & \\
\hline
\end{tabular}

Dari Tabel 2. Dapat di lihat hasil

\begin{tabular}{llllll}
\hline Model & B & $\begin{array}{l}\text { Std. } \\
\text { Error }\end{array}$ & Beta & t & Sig. \\
\cline { 2 - 6 } & & & & \\
\hline (Constant) & $-3,333$ & 5,843 & &,- 570 & 0,572 \\
Kerja Keras & 0,943 & 0,062 & 0,927 & 15,235 & 0,000 \\
\hline
\end{tabular}
signifikansi kerja keras dan juga hasil belajar
fisika didapatkan masing-masing yaitu 0,000 . Dari hasil tersebut dapat di lihat bahwa $0,000<$ 0,05 yang artinya kedua variabel berkorelasi. Kemudian, jika kita tinjau pada pearson correlation disitu didapatkan hasil 0,927 yang berarti derajat hubungan atau nilai pearson correlation masuk pada kategori korelasi sangat kuat. Disini, dapat di tarik kesimpuan bahwa tingkat kerja keras siswa dalam mata pelajaran fisika sangat berhubungan dan berpengaruh pada hasil belajar siswa (Kadir, 2015). Langkah selanjutnya, peneliti melakukan pengujian regresi linear sederhana yang bertujuan untuk menentukan diterima atau tidaknya hipotesis penelitian. Pengujian hipotesis ini dilakukan untuk melihat ada atau tidaknya pengaruh karakter kerja keras dalam mata pelajaran fisika terhadap hasil belajar fisika. Regresi linear sederhana merupakan sebuah metode statistik yang digunakan untuk menguji sejauh mana hubungan sebab akibat antar variabel (Katemba, 2017).

Adapun kriteria pengujian dalam uji regresi linear sederhana, apabila nilai signifikansi atau nilai probabilitasnya (p) lebih besar dari 0,05 maka $\mathrm{H}_{0}$ diterima dan $\mathrm{H}_{1}$ ditolak. Kemudian, jika nilai signifikansi atau nilai probabilitas (p) lebih kecil atau sama dengan 0,05 maka $\mathrm{H}_{0}$ ditolak dan $\mathrm{H}_{1}$ diterima (Kadir, 2015). Berikut ini adalah hasil uji regresi linear sederhana antar karakter kerja keras terhadap hasil belajar fisika.
Tabel 3. Hasil Varian Uji Pengaruh Karakter Kerja Keras terhadap Hasil Belajar Fisika

\begin{tabular}{cccccc}
\hline Model & $\begin{array}{c}\text { Sum of } \\
\text { Square }\end{array}$ & df & $\begin{array}{c}\text { Mean } \\
\text { Square }\end{array}$ & F & Sig. \\
\hline Regression & 979,530 & 1 & 979,530 & 232,101 & 0,000 \\
Residual & 160,370 & 38 & 4,220 & & \\
Total & 1139,900 & 39 & & & \\
\hline
\end{tabular}

Tabel 4. Hasil Koefisien Regresi Karakter Kerja Keras terhadap Hasil Belajar Fisika
Tabel 3. di atas menunjukkan hasil varian dengan nilai signifikansi/nilai probabilitasnya, yaitu: 0,000 . Artinya, berdasarkan hasil uji regrasi linear sederhana atau uji pengaruh yang dilakukan, maka dapat disimpulkan bahwa terdapat pengaruh kerja keras dalam mata pelajaran fisika terhadap hasil belajar/prestasi belajar siswa. Sebab, nilai signifikansi lebih kecil dari 0,05 yaitu 0,000 atau dapat ditulis $0,000<$ 0,05 .

Berdasarkan hasil uji pada Tabel 4, dapat diperoleh persamaan regresi yaitu dengan menggunakan persamaan umum $\mathrm{Y}=a+b X$, dimana $Y$ merupakan nilai yang diprediksikan atau variabel terikat berupa hasil belajar fisika, $a$ yaitu kostanta yang mempengaruhi hasil belajar dengan nol, dan $b$ adalah koefisien regresi, serta $X$ merupakan nilai dari variabel bebas yaitu berupa kerja keras dalam belajar fisika. Berdasarkan hasil analisis yang dilakukan diperoleh persamaan regresi $\mathrm{Y}=-3,33+0,943 X$. Dari hasil analisis diperoleh $\mathrm{t}_{\text {hit }}=15,235$ dan $\mathrm{p}$-value $=0,000 / 2=$ $0,000<0,05$. Dengan demikian H1 diterima dan H0 ditolak. Dengan demikian, dapat disimpulkan bahwa karakter kerja keras dalam mata pelajaran fisika berpengaruh positif pada prestasi ataupun hasil belajar siswa. Hal ini sejalan dengan penelitian Lasmita dan Kartina (2019) bahwa terdapat pengaruh positif antara siswa yang apabila variabel bebas berupa kerja keras sama 
memiliki karakter kerja keras dengan hasil belajar siswa dalam mata pelajaran IPA materi fisika..

\section{KESIMPULAN}

Berdasarkan penelitian yang telah dilakukan, maka dapat disimpulkan:

1. Dapat dilihat hasil signifikasnsi dari uji korelasi kerja keras dan juga dari hasil masingmasing yaitu 0,000 . Dapat hasil tersebut dapat dilihat bahwa $0,000<0,05$ yang artinya kedua variabel berkorelasi. Kemudian, jika ditinjau dari pearson correlation masuk pada kategori korelasi sangat kuat. Disini dapat ditarik kesimpulan bahwa tingkat kerja keras siswa dalam mata pelajaran fisika sangat berhubungan pada hasil belajar siswa.

2. Berdasarkan hasil analisis yang dilakukan diperoleh persamaan regresi $\mathrm{Y}=-3,33+$ $0,943 X$. dari hasil analisis diperoleh $t_{\text {hit }}=$ 15,235 dan $\mathrm{p}$-value $=0,000 / 2=0,000<$ 0,05 . Artinya, Karakter kerja keras dalam mata pelajaran fisika berpengaruh positif pada prestasi ataupun hasil belajar siswa khususnya pada aspek kognitif. Apabila siswa terbiasa untuk bekerja keras dalam memecahkan persoalan yang tepat pada mata pelajaran fisika maka hal ini dapat berpengaruh pada hasil belajarnya.

Berdasarkan hasil yang diperoleh, peneliti memberikan saran kepada guru bahwa sebaiknya para guru memperhatikan karakter kerja keras dalam diri siswa, karena hasil penelitian yang telah dilakukan menunjukkan bahwa karakter kerja keras dalam mata pelajaran fisika berpengaruh pada hasil belajar siswa. Adapun cara yang dapat dilakukan untuk meningkatkan dan menumbuhkan karakter kerja keras siswa, yaitu dengan cara memotivasi siswa, membimbing siswa dalam pembelajaran mandiri ataupun kelompok serta menciptakan suasana belajar yang menyenangkan dan membiasakan siswa aktif dalam pembelajaran, sehingga dengan demikian siswa dapat meningkatkan kemampuan secara optimal dan totalitas.

\section{DAFTAR PUSTAKA}

Al Munawwarah, A., \& Arafah, K. (2018). Pengaruh Metode Diskusi Kelompok Terhadap Hasil Belajar Fisika Peserta Didik
Kelas Xi Sma Negeri 8 Makassar. Jurnal Sains dan Pendidikan Fisika, 14(1).

Ariani, T. (2019). Perbedaan Hasil Belajar Fisika Menggunakan Model Pembelajaran Student Team Achievement Division (STAD) dan Model Pembelajaran Teams Games Tournament (TGT) Di SMP Negeri Air Lesing. Jurnal Sains dan Pendidikan Fisika, 14(2).

As'ari, Ruli. (2018). Pengetahuan dan Sikap Masyarakat dalam Melestarikan Lingkungan Hubungannya dengan Perilaku Menjaga Kelestarian Kawasan Bukit Sepuluh Ribu di Kota Tasikmalaya. Jurnal GeoEco. 4(1).

Fitriani, R., Kholilah, K., Rini, E. F. S., Pratiwi, M. R., Safitri, H., Syiarah, H., \& Ramadhanti, A. (2021). Analisis Karakter Kerja Keras Siswa Kelas XI IPA Di SMAN 1 Kota Jambi. PENDIPA Journal of Science Education, 5(2), 188-194.

Idris, N. W. (2020). Pengaruh Model Pembelajaran Berbasis Masalah Terhadap Kemampuan Berpikir Kritis Peserta Didik. Jurnal Sains dan Pendidikan Fisika, 16(1)

Kadir. (2015). Statistika Terapan Konsep, Contoh dan Analisis Data dengan Program SPSS/Lisrel dalam Penelitian. Jakarta : PT. Raja Grafindo Persada.

Katemba, Petrus \& Djoh, Rosita K. Prediksi Tingkat Produksi Kopi menggunakan Regresi Linear. Jurnal ilmiah FLASH. 3(1).

Kurniawan, D. A., \& Astalini, A. (2019). Evaluasi sikap siswa smp terhadap ipa di kabupaten muaro jambi. Jurnal Ilmiah Didaktika: Media Ilmiah Pendidikan dan Pengajaran, 19(1), 124-139.

Lasmita, L., \& Kartina, L. (2019). Pengaruh Karakter Kerja Keras Terhadap Prestasi Belajar Mata Pelajaran Ilmu Pengetahuan Alam Materi Fisika Di Kelas VIII SMP Negeri 2 Muaro Jambi. COMPTON: Jurnal Ilmiah Pendidikan Fisika, 6(1), 15-23.

Layuk, F. P. (2020). Pengaruh Metode Eksperimen Terhadap Motivasi Dan Hasil Belajar Fisika Sma Negeri 9 Makassar. Jurnal Sains dan Pendidikan Fisika, 16(1).

Mafudiansyah, M. (2020). Analisis Hasil Belajar Fisika Di Sma Negeri 3makassar. Jurnal Sains dan Pendidikan Fisika, 16(1). 
Mangamar, M., \& Oksaputra, M. F. (2019). Analisis Karakter Peduli Lingkungan Siswa Kelas VIII E dan VIII I SMPN 1 Kota Jambi. Jurnal Profesi Keguruan, 5(2), 137140.

Martawijaya, M. A., Jabir, J., \& Azis, A. (2019). Kemampuan Berpikir Lateral Dalam Memecahkan Masalah Fisika. Jurnal Sains dan Pendidikan Fisika, 15(1).

Marzuki, M., Azis, A., \& Sari, S. S. (2020). Penerapan Metode Problem Solving Terhadap Kemampuan Berpikir Kritis Peserta Didik Di Sma Negeri 3 Makassar. Jurnal Sains dan Pendidikan Fisika, 16(1).

Pangestu, A. D., Samparadja, H., \& Tiya, K. (2015). Pengaruh minat terhadap hasil belajar matematika siswa sma negeri 1 uluiwoi kabupaten kolaka timur. Jurnal Penelitian Pendidikan Matematika, 3(2), 17 26.

Pratomo, Y. I. F., \& Setyowati, K. (2016). Kepuasan Pengguna Layanan Kesehatan RSUD Kota Surakarta (Studi Deskriptif Kuantitatif Tingkat Kepuasan Pasien Rawat Jalan RSUD Kota Surakarta). Jurnal Wacana Publik, 1(2), 11-23.

Putra, D. S., \& Wiza, O. H. (2019). Analisis Sikap Siswa Terhadap Mata Pelajaran Fisika di SMA Ferdy Ferry Putra Kota Jambi. UPEJ Unnes Physics Education Journal, 8(3), 299311.

Putri Pratiwi, Taufanny. (2018). Pengaruh Motivasi dan Minat Belajar Peserta Didik Terhadap Prestasi Belajar Fisika di SMA Kemala Bhayangkari 01 Surabaya. Inovasi Pendidikan Fisika, 7(2).

Quanti, Prita. (2017). Pengembangan LKPD materi pokok Fluida Dinamis berbentuk Mini Majalah untuk Meningkatkan Prestasi dan Menumbuhkan Minat Belajar Fisika Peserta Didik SMA. Skripsi, Yogyakarta : Universitas Negeri Yogyakarta.
Ramadhan, P. R. (2019). Pengaruh Penerapan Standar Akuntansi Pemerintahan terhadap Kualitas Penyajian Laporan Keuangan pada Pemerintah Kabupaten Serdang Bedagai. In Seminar Nasional Taman Siswa Bima, 1(1), 147-153.

Rini, E. F. S., Wibisono, G., Ramadhanti, A., Simamora, N. N., \& Chen, D. (2020). Pengaruh Kemandirian Terhadap Prestasi Belajar Siswa Kelas XI di SMA Negeri 11 Kota Jambi. Jurnal Pendidikan Fisika dan Teknologi, 6(2), 256-263.

Sappaile, B. I. (2007). Pembobotan Butir Pernyataan Dalam Bentuk Skala Likert Dengan Pendekatan Distribusi Z. Jurnal Pendidikan Dan Kebudayaan, 13(64), 1-8.

Sari, C. E. (2020). Identifikasi Sikap Ilmiah Dalam Melakukan Praktikum Fisika Pada Peserta Didik Sman 12 Makassar. Jurnal Sains dan Pendidikan Fisika, 16(1).

Sari, N. (2020). Hubungan Kerja Keras dengan Sikap Siswa dalam Mata Pelajaran IPA di SMP se-Kecamatan Muara Bulian. Science Education Journal. 3(2), 101-111.

Sarlin, M. (2018). Analisis Minat Belajar Siswa terhadap PERubahan Hasil Belajar Ilmu Pengetahuan Sosial di SDN 104 Kota Utara Kota Gorontalo. Cokroaminoto Journal of Primary Education, 1(1).

Silahuddin, S. (2017). Urgensi Membangun Karakter Anak Sejak Usia Dini. Bunayya: Jurnal Pendidikan Anak, 3(2), 18-41.

Thahir, F., Herman, H., \& Khaeruddin, K. (2019). Kualitas Pembelajaran Fisika Di Sma Negeri 24 Bone. Jurnal Sains dan Pendidikan Fisika, 15(1).

Wijaya, P.A., Jasaruddin, J., \& Arafah, K. (2019). Kemampuan Peserta Didik Kelas X dalam Menyelesaikan Soal-Soal Kognitif Tipe Menganalisis dan Mengevaluasi pada Mata Pelajaran Fisika. Jurnal Sains dan Pendidikan Fisika, 15(1). 